\title{
A IMPLANTAÇÃO DE CONSÓRCIO MODULAR EM UMA INSTITUIÇÃO DE ENSINO NO RIO GRANDE DO SUL: UM ESTUDO DE CASO BASEADO NA INOVAÇÃO DA GESTÃO EDUCACIONAL E NA SUCESSÃO FAMILIAR
}

\author{
THE IMPLEMENTATION OF MODULAR CONSORTIUM IN A TEACHING INSTITUTION IN \\ RIO GRANDE DO SUL: A CASE STUDY BASED ON THE INNOVATION OF EDUCATIONAL \\ MANAGEMENT AND FAMILY SUCCESSION
}

\author{
Alexandre Braga ${ }^{1}$ \\ https://orcid.org/0000-0002-3841-5119
}

Submissão: 23/12/2020 / Aceito: 12/04/2021 / Publicado: 13/04/2021.

\begin{abstract}
Resumo
A presente pesquisa-ação tem como base principal a inovação na implantação de um método não convencional de sucessão em empresas familiares, inserido na gestão da empresa mãe e desmembrada em consórcio de três escolas. O objetivo do estudo é avaliar a aplicação de um consórcio modular no desmembramento de uma organização em três corporações modulistas, como ferramenta de apoio à sucessão familiar empresarial em empresas de pequeno e médio porte. $\mathrm{O}$ artigo defende a possibilidade de aceitação que a associação entre consórcio modular e o planejamento sucessório familiar pode promover uma estrutura empresarial sucessória mais efetiva do que os modelos de processos sucessórios tradicionais. Não foram encontrados estudos anteriores propondo a aplicação dos conceitos de modularização e sua derivação ao consórcio modular como ferramenta auxiliar em um processo sucessório familiar. Deste modo, este artigo torna-se pioneiro na proposição de união destes dois temas. Como resultados, no tocante especialmente à sucessão familiar, o consórcio modular obteve êxito para a finalidade que foi proposto, de modo que fundadores e sucessores demonstram satisfação com os resultados alcançados.
\end{abstract}

Palavras-chave: Sucessão. Modularização. Escolas.

\begin{abstract}
The present research-action has as main base the innovation in the implantation of an unconventional method of succession in family businesses, inserted in the management of the parent company and split into a consortium of three modulist schools. The objective of the study is to evaluate the application of a modular consortium in the break-up of a parent company into three modular companies, as a tool to support family business succession in small and medium-sized companies. The article defends the possibility of acceptance that the association between modular consortium and family succession planning can promote a more effective succession business structure than traditional succession process models. No previous studies were found proposing the application of the concepts of modularization and its derivation to the modular consortium as an auxiliary tool in a family succession process. In this way, this article becomes a pioneer in proposing the union of these two themes. As a result, especially with regard to family succession, the modular consortium was successful
\end{abstract}

${ }^{1}$ Doutor em Administração. Professor Adjunto na Universidade Federal de Pelotas. bragaufpel@gmail.com 
for the purpose that was proposed, so that founders and successors demonstrate satisfaction with the results achieved.

Keywords: Succession. Modularization. Schools.

\section{INTRODUÇÃO}

De acordo com Martins et al. (2014), a empresa familiar define-se como sendo o alicerce para que as sociedades cresçam e se desenvolvam. O desenvolvimento dessas organizações requer uma gestão empreendedora e inovadora, assim como em qualquer outra.

O Serviço Brasileiro de Apoio às Micro e Pequenas Empresas (SEBRAE, 2016) apontou que quase $80 \%$ das corporações são consideradas familiares. O mesmo estudo mostrou que apenas $25 \%$ conseguem passar o negócio para outra geração e menos de $10 \%$ para a $4^{\circ}$ geração. Isso revela que o processo de transição no poder não é simples. Gersick et. al. (1997), por sua vez, ressaltam similar relevância em âmbito mundial, ao noticiarem que em torno de $40 \%$ das 500 maiores companhias nominadas na revista Fortune são de propriedade familiar ou controladas por famílias, representando a geração de metade do Produto Nacional Bruto dos EUA e empregando $50 \%$ da força de trabalho desse país. Na Europa, chegam a compor a maioria dos grandes empreendimentos, e na América Latina, constituem a principal forma de propriedade privada na maioria dos setores.

Para Floriani e Rodrigues (2000) uma das questões mais problemáticas nas empresas familiares é a falta de planejamento sucessório. Existe uma grande diferença entre aquele que herda por disposição legal, daquele que o faz por vontade de quem está dispondo de seus bens. Ou seja, que decididamente cabe ao sucedido definir as regras da sua sucessão, planejando-a antes que esta se faça obrigatória por força de lei (em caso de morte ou impedimento permanente, por exemplo). A questão, contudo, é que parece ser muito elevado o número de fundadores que não atentam para a sucessão, tornando-a muito mais um problema do que um processo de continuidade.

Embora existam investigações teóricas e empíricas sobre consórcio modular, os estudos sobre este tema estão fortemente relacionados à indústria automobilística (BRAGA, 2015). Não foram encontrados estudos propondo a aplicação dos conceitos de modularização e sua derivação ao consórcio modular como ferramenta auxiliar em um processo sucessório familiar. Deste modo este artigo torna-se pioneiro na proposição de união destes dois temas, a sucessão familiar empresarial e o consórcio modular. 
Deste modo, é importante ressaltar que o presente estudo não trata da modularização de currículos, assunto este amplamente debatido e tratado principalmente nas esferas pedagógicas do ensino profissionalizante, mas sim da aplicação dos conceitos de modularização empresarial, como ferramenta de auxílio à sucessão familiar. São assuntos completamente distintos. Portanto, partido deste aspecto, o presente artigo tem como base principal a inovação na implantação de um método não convencional de sucessão em empresas familiares, inserido na gestão da empresa mãe e desmembrada em consórcio de três escolas modulistas.

Como estratégia interorganizacional, o conceito de consórcio modular induz as empresas a ultrapassarem as fronteiras organizacionais, no intuito de permitir que toda a cadeia de valor se torne mais eficiente (BRAGA, 2015). O presente estudo, defende a possibilidade de aceitação que a associação entre consórcio modular e o planejamento sucessório familiar pode promover uma estrutura empresarial sucessória mais efetiva do que os modelos de processos sucessórios tradicionais.

Diante do exposto, a problemática que se coloca aos pesquisadores e demais interessados no assunto, seria se é possível adotar a estratégia de consórcio no ramo escolar, como ferramenta válida no apoio à sucessão familiar.

Sendo assim, o objetivo principal do presente estudo é avaliar a aplicação de um consórcio modular no desmembramento de uma empresa-mãe em três empresas modulistas, como ferramenta de apoio à sucessão familiar empresarial em empresas de pequeno e médio porte.

\section{FUNDAMENTAÇÃO TEÓRICA}

\section{Sucessão Familiar}

Para Lodi (1998), um programa sucessório satisfatório está correlacionado com a maneira que o pai, sendo o presidente da empresa, realizou o ato de planejar a sua família para o poder e a riqueza. Os herdeiros precisam ser preparados para o processo sucessório, para que suas expectativas sejam atendidas, visto que a contínua motivação é fator chave para que a segunda geração tome frente dos negócios. Portanto, conclui-se que a geração que seguirá na gestão da empresa familiar, dando continuidade aos negócios e sonhos do fundador, precisa estar inteirada ao processo de gestão.

Ventura (1993) aponta os processos de sucessão mal (ou não) planejados e malsucedidos como as principais causas da vida curta de empresas familiares. Ele indica, ainda, um estudo realizado nos Estados Unidos, que mostrou que apesar do número de 
empresas familiares ser muito grande elas têm vida curta, ou seja, uma expectativa média de vida de apenas 24 anos, em contraposição com uma vida média de 45 anos de empresas não familiares.

Este mesmo estudo mostrou que, para cada duas empresas familiares que continuam com a segunda geração, quatro não o fazem; e que, dessas duas que são bem sucedidas, só uma delas passa para a terceira geração. Assim, pode-se expressar esses quatro elementos ordenadamente, como na Figura 1.

Figura 1: Componentes do Processo Sucessório

\begin{tabular}{|c|c|c|c|}
\hline A Família & A Empresa & $\begin{array}{c}\text { A Empresa } \\
\text { Familiar }\end{array}$ & $\begin{array}{c}\text { O Plano } \\
\text { Sucessório }\end{array}$ \\
\hline $\begin{array}{l}\text { - Unidade social } \\
\text { - Valores passados } \\
\text { de geração para } \\
\text { geração } \\
\text { - } \quad \text { Histórico familiar } \\
\text { Berço do } \\
\text { fundador e seus } \\
\text { herdeiros e } \\
\text { sucessores }\end{array}$ & 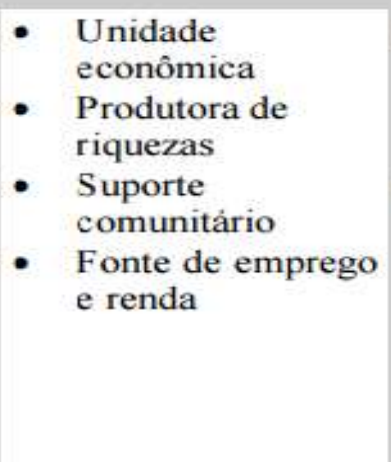 & $\begin{array}{l}\text { Representativa de } \\
\text { grande parcela da } \\
\text { economia } \\
\text { mundial } \\
\text { Responsável pela } \\
\text { manutenção e } \\
\text { estabilidade de } \\
\text { grande parte do } \\
\text { mercado } \\
\text { econômico e de } \\
\text { igual parcela da } \\
\text { sociedade }\end{array}$ & $\begin{array}{l}\text { Envolve: a } \\
\text { familia, a } \\
\text { propriedade e a } \\
\text { administração } \\
\text { Possibilita a } \\
\text { perpetuação da } \\
\text { organização, } \\
\text { quando bem } \\
\text { elaborado e bem } \\
\text { sucedido }\end{array}$ \\
\hline
\end{tabular}

Fonte: Floriani e Rodrigues (2000)

Bernhoeft (1996), comenta que não se pode misturar as figuras, os direitos e os deveres de membro da família, acionista e gestor da empresa familiar, sob pena de se permitir a instalação de conflitos de interesses entre os membros da família, prejudicando e colocando em risco o processo sucessório e o sucesso do negócio.

A sucessão representa o poder de continuidade de um nome de família. Ela representa a história de vida e a estruturação patrimonial ao longo das gerações que se sucedem. Gersick e Rosas (1997) elaboraram, como forma de desenvolver um modelo em que as relações das empresas familiares fossem descritas, o "Modelo Três Círculos".

Figura 2 - Modelo Três Círculos nas empresas familiares

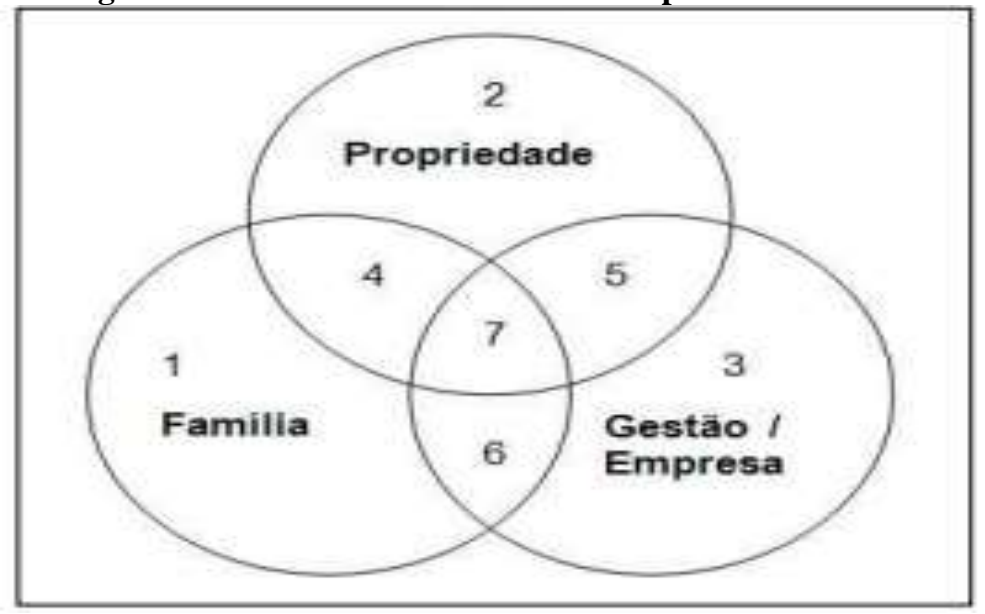

Fonte: Gersick e Rosas (1997) 
Os autores afirmam que compreender o sistema de uma empresa familiar com a sobreposição dos subsistemas da família, da propriedade e da gestão é essencial, e, com ele, é possível perceber os conflitos entre os membros, as prioridades, os impasses dos papéis desempenhados e os limites nessas empresas familiares. Através do modelo descrito, de acordo com Hunger (2016) pode-se localizar qualquer membro em uma das sete áreas envolvidas. Quem, por exemplo, está localizado no setor 1, entende-se que faz parte da família, mas não detém da propriedade nem faz parte da gestão da empresa.

Dentro da área numerada como 2 está o indivíduo que não pertence à família controladora e não faz parte da gestão da empresa, mas detém participação acionária. No número 3, é a pessoa de fora da família, que participa da gestão da empresa, mas não detém parte na propriedade. No setor 4 está um membro da família, atuando na gestão, sem parte acionária. Quem se localiza no setor 5 é membro da família, tem direito na propriedade mas não atua na gestão da empresa. Na área de número 6 o indivíduo não é membro da família, mas detém parte acionária e participa da gestão. Quem se localiza no setor 7 é membro da família, atuando na gestão com parte na propriedade. Portanto, devido a complexidade envolvida em uma empresa familiar, o modelo elaborado por Gersick e Rosas (1997), auxilia na resolução de possíveis conflitos e interesses no âmbito das intersecções familiares, visto que permite enxergar de forma mais clara as áreas de interesse no envolvimento da empresa familiar.

A literatura sobre empresas familiares aponta a sucessão como sendo um processo que, na visão dos autores supracitados se caracteriza como a quarta e última fase de uma empresa familiar, marcada por constante preocupação com o momento da transição. Mesmo que as empresas não estejam preparadas, as transições vão ocorrer e os ciclos recomeçar. Para Lodi (1993) e Gersick e Rosas (1997), a sucessão familiar é uma transferência de poder, geralmente conduzida em períodos de três a cinco anos, e preparada ao longo de uma geração. Sendo assim, para Tillmann e Grzybovski (2005), a sucessão não pode ser vista como "uma fase", mas como um conjunto de estratégias deliberadas no seio familiar e, em momento oportuno, apresentadas à empresa. seguintes:

Segundo Longenecker (1997), os sete estágios do processo sucessório são os

- Estágio pré-empresarial: não há planejamento formal na preparação da criança nesse período, quando ela pode ter apenas quatro ou cinco anos de idade, sendo um preparo para a próxima etapa;

- Estágio introdutório: difere do estágio I, no sentido de que os membros da família apresentam deliberadamente a criança para certas pessoas, associadas direta ou indiretamente à empresa, e lhe mostram outros aspectos relacionados aos negócios;

- Estágio funcional introdutório: o filho começa a trabalhar como empregado em tempo parcial. Isso ocorre frequentemente durante períodos de férias, ou diariamente, depois das aulas. Nessa fase, o filho passa a conhecer alguns indivíduos-chave empregados na empresa. $\mathrm{O}$ estágio funcional introdutório inclui a preparação educacional e a experiência que o filho ganha em outras organizações;

- Estágio funcional: começa quando o sucessor assume o emprego em tempo integral, após concluir sua formação educacional. Antes de passar a um posto 
gerencial, o sucessor pode trabalhar como contador, vendedor ou funcionário do estoque e possivelmente adquirir experiência em diversas outras funções;

- Estágio funcional avançado: ocorre quando o sucessor assume tarefas de supervisão, envolvendo a direção do trabalho dos empregados, mas não a administração-geral da empresa;

- Estágio de sucessão: nesse estágio o filho é nomeado presidente ou gerente geral dos negócios. Nesse ponto, ele exerce, presumivelmente, a direção-geral dos negócios, mas o pai ainda está lhe dando apoio. O sucessor não dominou, necessariamente, as complexidades da presidência, e o predecessor pode estar relutante em abrir mão de todas as decisões;

- Estágio maduro de sucessão: é atingido quando o processo de transição se completou, e o sucessor é tanto líder de fato quanto nominalmente.

\section{Alianças, Colaboração e Competitividade}

No atual cenário empresarial, tem sido crescente o número de alianças estratégicas formadas pelas organizações, bem como tem aumentado substancialmente a relevância do papel que elas representam dentro das estratégias empresariais. Tal fato decorre de diferentes fatores. Para Caldeira (2004), um deles é o desenvolvimento de novas tecnologias e sua rápida difusão; outro, é o processo de globalização dos mercados que tem levado a um acirramento da concorrência e à convergência dos gostos dos consumidores - cada vez mais exigentes e diversificados em suas necessidades e preferências.

À medida que as empresas se deparam com um ambiente crescentemente competitivo, complexo, globalizado e tecnologicamente incerto, existe uma maior necessidade de fornecer ao mercado respostas dinâmicas, flexíveis e rápidas. Sendo assim, "em virtude dessas novas exigências, as empresas voltam-se cada vez mais para ações cooperativas por meio da formação de alianças estratégicas" (MILES; PREECE; BAETZ, 1999 apud CALDEIRA, 2004).

Para tanto, as empresas passam a unir-se em alianças estratégicas em que utilizam a lógica de "cooperar para competir", por meio do compartilhamento e da colaboração mútua. As alianças têm sido descritas como sendo empregadas para objetivos ofensivos e defensivos. Chen (1996) argumenta que os antecedentes do comportamento competitivo incluem tanto uma habilidade para colocar em prática uma estratégia quanto às razões por trás de tal estratégia. Usando essa linha de pensamento, gerentes podem utilizar-se de alianças para entrar nos mercados de seus competidores. Quando as alianças envolvem empresas do mesmo setor, elas podem ser o meio por intermédio do qual uma empresa começa a implementar uma estratégia para terceirizar atividades criadoras de valor que ela inicialmente conduzia sozinha (DYER e SINGH, 1998). Enquanto as empresas tornam-se verticalmente menos integradas, encontra-se um aumento no número de relacionamentos "compradorfornecedor" de longo prazo - outra forma de aliança diática.

Doz e Hamel (1998) descrevem três motivações genéricas por trás das muitas alianças por eles estudadas: co-especialização, co-opção e co-aprendizagem. Em algumas instâncias, as empresas apenas buscam uma destas três motivações, porém, em muitos casos, a busca pelos benefícios derivados de todas as três é o que motivou a aliança. Castells (1996) argumentou que o processo de globalização provoca um aniquilamento do espaço pelo tempo. $\mathrm{O}$ espaço estaria estruturado dentro de espaços de redes. $\mathrm{O}$ tempo tem sido mudado sob as condições da revolução digital, que tornou possível o desenvolvimento de uma lógica 
de rede que prevê complexidade de interações e padrões imprevisíveis. Dessa maneira, a lógica e o significado dos lugares passam a ser absorvida pelas redes.

Dyer e Nobeoka (2000) alegam que a inclinação de aprendizagem de uma firma vai além da sua capacidade como entidade única, isolada, necessitando, para tanto, da análise da rede em que a empresa está inserida. Os autores argumentam que essas redes podem ser meios eficazes de aprendizagem interorganizacional em que os clientes e fornecedores podem vir a serem fontes primárias de inovação. Além disso, a empresa deve ser capaz de criar e de posicionar-se nessas redes de aprendizagem como elemento aglutinador e coordenador, pela criação de rotinas institucionalizadas para o compartilhamento de conhecimento entre os membros participantes.

Coletivamente, essas rotinas podem ser vistas como a capacidade da rede de gerenciar os fluxos de conhecimento tácito, que são conhecimentos complexos e de difícil transferência e codificação, entre os elementos da rede. A rede deve ser capaz de criar uma forte identidade de rede, com regras de entrada e participação, em que a produção de conhecimento é vista como sua propriedade e, portanto, compartilhada por todos seus membros. Assim, abordam o aprendizado organizacional como fator-chave para alcançar-se vantagem competitiva sustentável.

Dyer e Singh (1998) argumentam que outros estudiosos que defendem a visão da organização baseada no conhecimento alegam que o papel-chave da organização é a criação, a armazenagem, e a aplicação de conhecimento. Embora a literatura sobre aprendizado organizacional foque na organização individual, há uma crescente evidência que sugere que a rede interorganizacional seja crítica, porém pouco compreendida como unidade de análise para entender-se o nível de aprendizado organizacional. Nesse aspecto, o aprendizado interorganizacional é fator crítico para o sucesso competitivo, haja vista que as organizações aprendem pela colaboração com outras empresas, assim como pela observação e importação de suas práticas.

\section{Inovação}

Para Antunes Jr. et al. (2009), inovar é a principal opção estratégica para alavancar a competitividade das empresas e, por intermédio delas, promover o desenvolvimento econômico. É com a inovação que a empresa adquire forças para competir e para inserir se em novos mercados seja em termos de produto, seja em termos geográficos.

As principais inovações relacionadas ao estudo de caso em tela são as seguintes:

(a) As inovações organizacionais - podem visar à melhoria do desempenho de uma empresa por meio da redução de custos administrativos ou de custos operacionais, melhorando a satisfação no local de trabalho (e assim a produtividade), obtendo acess o a recursos não negociáveis (como o conhecimento externo não codificado e outros ganhos relacionais) ou reduzindo os custos de suprimentos. Elas se referem a um método organizacional que não tenha sido usado anteriormente na empresa e que seja o resultado de decisões estratégicas tomadas pela gerência.

(b) As inovações de processo - podem visar a: (i) reduzir 'custos' totais ou unitários de produção ou de distribuição; (ii) melhorar a 'qualidade' ou o 'atendimento' (prazos, velocidade, flexibilidade); e (iii) produzir ou distribuir produtos novos ou significativamente melhorados.

As inovações na organização do local de trabalho envolvem a implementação de novas estruturas organizacionais e métodos para distribuir (ou concentrar) 
responsabilidades e poder de decisão entre funções, cargos e atividades. Também se pode considerar, como inovações organizacionais, novos métodos nas relações externas de uma empresa que compreendem a implementação de novos meios para organizar o relacionamento com outras firmas e com outros atores (universidades, governo, organizações financeiras, entre outros).

A Figura 3 ilustra que existem oportunidades para inovar em todas as atividades ao longo de uma cadeia de valor, ou seja, explicita que a inovação pode e deve ocorrer em todas as funções do negócio da empresa. Ela apresenta os tipos básicos de inovação que ocorrem ao longo da cadeia de valor.

Figura 3 - Tipos de inovação ao longo de uma Cadeia de Valor

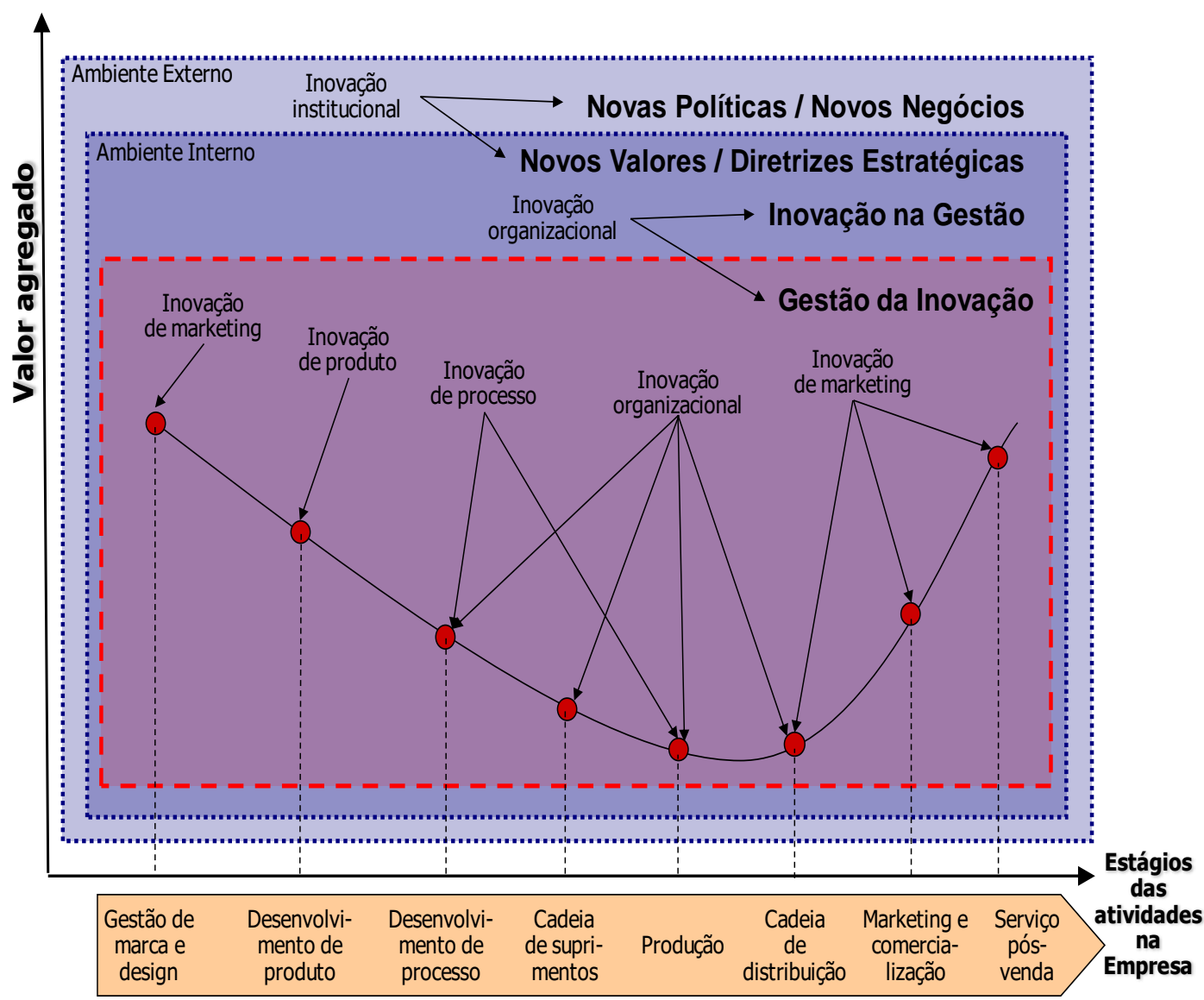

Fonte: Antunes et al. (2007).

Para Boer e During (2001), apud Braga (2015), o sucesso na inovação e na difusão de um paradigma tecnológico implica em emergência de uma nova estrutura de custos entre as firmas de um setor. As inovações tecnológicas introduzidas pelas firmas são capazes de alterar as estruturas industriais setoriais, em termos de tamanho das firmas, preços relativos e concentração. Assim, o resultado de distintas aptidões tecnológicas faz com que as firmas apresentem uma diversidade no processo de inovação, o que resultará em assimetrias e variedades tecnológicas. Essa heterogeneidade nos processos de inovação é resultado de que as firmas geram, utilizam, absorvem, desenvolvem e transferem tecnologias diferentemente uma das outras, para produção de produtos, 
fundando estruturas industriais com diferentes padrões de inovação da qual elas fazem parte. Para Zawislak (1996), a inovação ocorre por meio das formas de aprendizado que a firma realiza, ou seja, é mediante o aprendizado que se dá a constituição do processo inovativo.

Nesse sentido, para Tidd (2001) e Antunes Jr. et al. (2009), é possível afirmar que alguns aspectos relevantes relacionados ao conceito de inovação são: (a) a ideia de que a inovação está associada diretamente com a competitividade das empresas; (b) o entendimento de produtos como novos produtos no mesmo espaço geográfico ou os mesmos em novos espaços geográficos, ou, ainda, novos produtos em novos espaços geográficos, e a noção de que a inovação é essencial para abrir novos mercados; e (c) a perspectiva de que a inovação está associad a com a criatividade individual, em particular, e com a aprendizagem organizacional, em geral.

\section{Modularização e Consórcio Modular}

Para Braga (2015) a estratégia de modularização tem como objetivo desenvolver arquiteturas de produto que contenham unidades fisicamente destacáveis, denominados módulos, de forma a permitir que estas unidades sejam utilizadas em variações de um produto ou em linhas de produtos diferentes. Com esse propósito, métodos e técnicas de modularização foram criados e precisam ser adaptados às características de cada projeto, como a natureza do negócio, a complexidade e a novidade do produto ou serviço desenvolvido.

Pelegrini (2005) afirma que na modularização, a solução final de um problema é obtida por meio de soluções de subproblemas, o que permite dividir o programa/empresa/atividade em tantos módulos quanto necessário para a regulação do sistema, com subfunções claramente delimitadas, que podem, inclusive, ser implementados, separadamente, por diversos gestores de uma equipe ou de várias equipes. Assim, a modularização surgiu para promover um melhor gerenciamento por meio da decomposição da complexidade dos modelos produtivos, bem como para atender as exigências dos consumidores (BERNARDES et al., 2013).

A modularização proporciona uma série de vantagens estratégicas que, quando bem desenvolvidas e administradas, podem proporcionar um diferencial competitivo significativo para a empresa. Em uma revisão bibliográfica sobre o assunto, Fixson (2003) aponta duas principais abordagens estratégicas sobre o tema: (1) a estratégia de modularização orientada para o mercado; e (2) a estratégia de modularização orientada para a tecnologia. No entanto, Pelegrini (2005) comenta que Fixson não coloca as estratégias sob o ponto de vista da empresa, o que seria igualmente adequado e concernente ao presente estudo. Para Miller e Elgard (1998), modularidade é um atributo de um sistema relacionado a sua estrutura e funcionalidade. Uma estrutura modular consiste na junção de unidades funcionais distintas (módulos) por meio de interfaces e interações padronizadas. Assim, a modularização pode ser entendida como a atividade (ou o processo) de estruturação e padronização dos módulos.

Miller e Elgard (1998) afirmam que não se pode definir um módulo a partir do próprio módulo. Assim, para os autores, não se consegue encontrar a modularidade se não é conhecido o sistema para o qual o módulo pertence. Mas, ao mesmo tempo, o módulo em si tem de possuir essencialmente uma funcionalidade bem definida.

A definição sobre o que constitui realmente um módulo, e consequentemente a modularização, é ainda uma área de debates e discussão. Segundo Doran et al. (2007) a 
modularização é um termo vagamente definido e ambiguamente usado na indústria automobilística, aplicável e aplicado a um número de sistemas (design de produto, fabricação, organização do trabalho etc.). O objetivo da modularidade é alcançar um produto em que os diferentes módulos sejam independentes uns dos outros, conectando-se por meio de interfaces especificadas e padronizadas, possibilitando alterações individuais, sem que seja necessário interferir nos demais módulos (MIKKOLA, 2006).

Para Sako e Murray (2000), a abordagem modular pode ser uma estratégia que pode levar uma organização a reter, desenvolver e descartar diferentes capacidades. Nesse sentido, Villela (2009) ressalta que, ao constituir uma rede, o grupo poderia construir conhecimento conjunto seja formal, seja informal, e disponibilizar recursos que permitam limitar ações de oportunistas contra o grupo.

\section{METODOLOGIA}

O presente trabalho, de cunho qualitativo, caracteriza-se da seguinte maneira: (a) quanto aos objetivos: exploratório, intervencionista e explicativo; (b) quanto aos meios: estudo de caso (EISENHARDT, 1989), ou ainda, estudo de caso único com objetos incorporados (BRAGA, 2015). Ainda se caracteriza, no tocante aos procedimentos técnicos, como uma abordagem de pesquisa-ação. Pesquisa-ação é, principalmente, uma estratégia para o desenvolvimento de professores e pesquisadores de modo que eles possam utilizar suas pesquisas para aprimorar seu ensino e, em decorrência, o aprendizado de seus alunos (SACHS, 2003).

De uma perspectiva puramente prática, a pesquisa-ação funciona melhor com cooperação e colaboração porque os efeitos da prática de um indivíduo isolado sobre uma organização jamais se limitam àquele indivíduo. A pesquisa-ação praticada individualmente pode criar um problema que Senge (1990) identifica com o "dilema nuclear da aprendizagem": aprendemos melhor com a experiência, mas não podemos fazê-lo se não vivenciamos as consequências de muitas de nossas decisões mais importantes nem podemos nos introduzir nas experiências dos que o fazem. Dessa forma o objetivo da pesquisa-ação é juntar teoria, pelo lado do pesquisador e prática, pelo lado da empresa, com a possibilidade de estudar o objeto e identificar razões de como e por que determinadas técnicas são utilizadas, sempre com o propósito de gerar contribuições teóricas relevantes (WESTIN \& ROBERTS, 2010 apud OYADOMARI, 2015).

Este tipo de pesquisa tem como principais características o uso deliberado de observações, ações em uma situação de campo, experimental e não controlada, observação de processos e resultados e análise à luz da literatura, muito embora o aspecto que a diferencia 
das outras pesquisas, seu diferencial, é a construção de um experimento de campo (JÖNSSON \& LUKKA, 2007 apud OYADOMARI, 2015), com o pesquisador tendo a oportunidade de coletar material que não estaria acessível por meio dos métodos tradicionais de pesquisa.

Mais uma das características deste tipo de pesquisa é o seu aspecto colaborativo entre pesquisadores e práticos. A colaboração se justifica uma vez que os práticos possuem interesses similares aos dos pesquisadores na busca de um entendimento dos modelos organizacionais que possam explicar com propriedade os resultados dessas experiências. $\mathrm{O}$ que também é confirmado por Baardi (2010) para quem os dois objetivos dessa abordagem são avançar o conhecimento em seu campo e ajudar a melhorar o sistema estudado, através de observações diretas e indiretas, análise documental, questionários e entrevistas com todas áreas da empresa que sejam necessárias para o real diagnóstico da situação e das possíveis propostas de melhoria.

Esta pesquisa-ação teve início em 2011, com o objetivo do pesquisador em testar um modelo de consórcio modular em objeto empírico distinto das pesquisas correntes, que utilizam desta estratégia, principalmente, na indústria automobilística. Como o maior laboratório de pesquisas em administração são as organizações, interesses mútuos, porém razoavelmente distintos, um de motivação acadêmica e outro de motivação profissional e familiar, acabaram por iniciar esta demanda. Este estudo se caracteriza, portanto, pela singularidade da união de dois temas até o momento não testados em conjunto: a modularização e a sucessão familiar, onde o pesquisador acaba por testar novas teorias e estratégias para o segmento de atuação da empresa, e participa ativamente unicamente como cientista e não como consultor, pela oportunidade fornecida pela organização de testar sua proposição.

No mesmo sentido, Roesh (2001) conceitua pesquisa-ação como uma estratégia de pesquisa que permite obter conhecimento sobre a realidade social empírica. Assim, o pesquisador poderá desenvolver componentes analíticos e categóricos de explicação, a partir dos dados coletados, não devendo ser confundido com consultoria. Deste modo, os dados revelados e o suporte da literatura da área sugerem a necessidade de se ir contra a tendência de se reduzir a pesquisa-ação a um mero trabalho de consultoria (BLOCH-POULSEN; KRISTIANSEN, 2011), pois os objetivos da atuação de um pesquisador são testar hipóteses, sendo amparado pela teoria e pela filosofia, e não simplesmente pela prática. 
Alguns riscos ou possíveis desvantagens da pesquisa-ação envolvem principalmente a relação custo $\mathrm{x}$ benefício, uma vez que o tempo médio de pesquisas com essa abordagem varia de 2 a 6 anos, o que prejudica o desempenho de pesquisadores no curto prazo (SUOMALA e LYLY-YRJÄNÄINEN, 2010), mas os ganhos em termos de profundidade e possibilidades em avanços da teoria e em descortinarem-se possíveis novas práticas de gestão, podem trazer contribuições satisfatórias, mais que proporcionais ao investimento de tempo e dedicação do pesquisador.

\section{ANÁLISE DOS RESULTADOS}

\section{A empresa familiar e a necessidade da sucessão}

A escola privada objeto do presente trabalho, foi criada por um casal de professores em 1995, e iniciou suas atividades somente oferecendo a modalidade de ensino médio. Passados cerca de 7 anos, a escola decidiu oferecer a modalidade de educação fundamental e, dois anos depois, implantou a educação infantil. Deste modo, no ano de 2004, se tornou uma escola completa, oferecendo todos os três níveis de formação básica autorizados pelo Ministério da Educação.

Passados vinte anos da criação da escola, a empresa encontrava-se saudável financeiramente e detinha um marketshare significativo em termos de número de alunos matriculados na cidade de sua sede. No entendimento dos fundadores, era momento de estabilidade e consolidação, propício para um planejamento de longo prazo.

Sendo assim, os fundadores decidiram que seria pertinente iniciar o planejamento sucessório familiar com os seus três filhos, e gostariam de que o formato da sucessão fosse o mais justo e menos conflituoso possível, de modo a mitigar focos de competição e de divisão familiar, na luta pelo poder e pela participação nos destinos da organização.

\section{Adaptação do conceito de consórcio modular tradicional para o consórcio modular educacional}

Sabidamente os conceitos e práticas de modularização e sua derivação para consórcio modular foram criados para fábricas de componentes multivariados. Especialmente a 
indústria automobilística se incorporou aos conceitos de modularização e adaptações de plantas até a aplicação de condomínios integrados e consórcios modulares.

Um modelo de integração foi apresentado por Bennet e Klug (2012), contendo cinco tipos de integração, e a integração tipo consórcio modular é o mais alto tipo de integração. A operação de montagem como um todo é dividida em módulos separados, sob a responsabilidade do fornecedor sobre cada uma delas. Portanto, os supostos fornecedores, agora denominados de modulistas, não simplesmente montam os módulos, mas também realizam a montagem final do produto. No tipo consórcio modular completo, o fabricante foca no planejamento, no design, na engenharia, na certeza da qualidade, na coordenação e na administração. Dessa forma, a o fabricante não se envolve nas operações de montagem, mas é responsável pela inspeção final dos produtos completos.

O grande desafio do presente estudo é justamente a substituição do objeto empírico em questão. De fábricas para uma escola. Sendo assim, a adaptação inicial do conceito de Bennet e Klug (2012) seria no que concerne ao que normalmente e tradicionalmente se traduz, na gestão da cadeia de suprimentos, em o que é linha de montagem, produto e modulista. Supondo os níveis formais de educação básica como uma linha de formação/montagem, o produto como sendo o aluno e o modulista como sendo a escola, é possível observar que um consórcio modular educacional poderia ser montado da seguinte forma:

Figura 4: Fluxograma dos níveis formais da educação básica e a adaptação à concepção de modelo de módulos

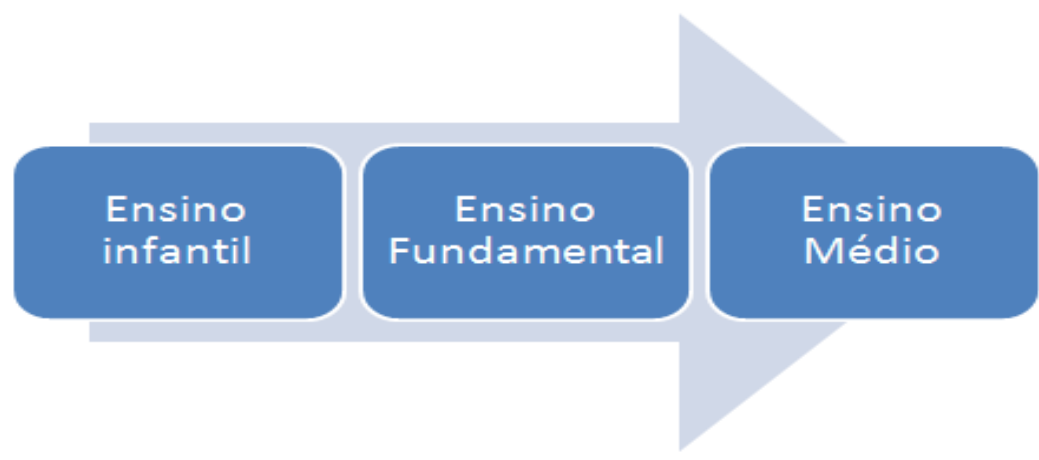

Fonte: $\mathrm{O}$ autor. 
Sendo assim, a lógica aplicada foi de desmembrar a escola-mãe em três escolas distintas, sendo cada escola um modulista, unindo as escolas em um modelo de consórcio modular, tal como estudado por Braga (2015) e adaptado na figura que segue.

Figura 5: Consórcio Modular Educacional

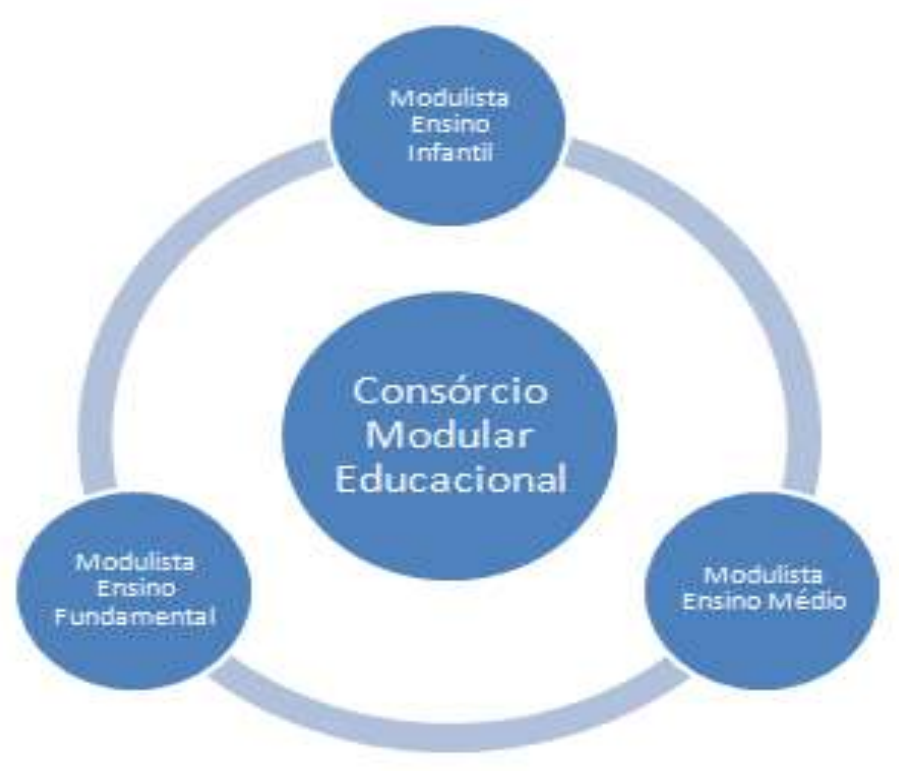

Fonte: $\mathrm{O}$ autor.

Salienta-se que a gestão de operações por intermédio da implantação de consórcios modulares agrega estratégias que incluem localização, gerenciamento da cadeia de suprimentos e gerenciamento de estoques, entre outros. Dessa forma, para Oliveira e Martins (2008), o consórcio modular consegue agregar diversas das principais prioridades competitivas de um negócio.

A localização dos modulistas, no caso as três escolas, partiu da separação da área física existente em três ambientes distintos, porém interligados quando necessário pedagogicamente. O ponto forte neste caso foi a escola-mãe ter uma área anexa que estava ociosa, onde foram erguidos novos prédios e novas áreas de lazer e desporto. $\mathrm{O}$ gerenciamento da cadeia será melhor explicado no tópico seguinte, que tratará dos limites, responsabilidades e diretrizes pedagógicas e gerenciais de cada modulista, e da gestão interorganizacional do consórcio. O gerenciamento de estoques, tanto mais neste caso, pode ser caracterizado como "estoque de alunos" e "estoque de professores, coordenadores e diretores" do que somente estoques de materiais didáticos e de expediente. O principal ativo 
na composição de um prestador de serviços educacionais é intangível, refletido como o conhecimento de seu corpo docente e know-how pedagógico institucional. É mais uma quebra de paradigmas no que tange aos conceitos tradicionais na gestão da cadeia de suprimentos. Mas quando se trata de gestão da cadeia de valor, os conceitos parecem melhor adaptáveis.

\section{A criação do consórcio}

Conforme comentado anteriormente, o consórcio modular foi criado dividindo a escola-mãe em três escolas distintas, tal como demonstrado na figura 5. A escolha pela modularização a partir dos três níveis da educação básica brasileira acabou por descortinar um problema que antes não era visto como tal: a diferença no número de alunos e o consequente faturamento de cada nível de educação que a escola oferecia. Deste modo, ao serem criados os módulos, a distribuição percentual de faturamento para cada modulista ficou da seguinte maneira: 26,3\% para o modulista da educação infantil, 51,1\% para o modulista da educação fundamental e 22,6\% para o modulista do ensino médio. A questão era de como equalizar os módulos de maneira a distribuir de forma o mais equânime possível a parte de cada sucessor no consórcio.

A distribuição dos módulos para os sucessores foi realizada de forma gradual, ficando ainda o módulo de ensino médio sob comando dos fundadores. A divisão foi realizada da seguinte maneira: um sucessor ficaria com o módulo infantil e os outros dois sucessores ficariam sócios no módulo fundamental. Desta maneira o problema da proporção na distribuição patrimonial seria contornado.

Cada uma das empresas modulistas obteve autonomia administrativa, financeira e pedagógica, de modo que até mesmo o enquadramento fiscal foi distinto entre os consorciados, devido ao faturamento de cada escola. Os fundadores assumiram figura, informalmente, como conselheiros na administração das escolas repassadas aos sucessores, de forma que as decisões operacionais fossem compartilhadas com os fundadores, de modo a seguirem orientando e transmitindo conhecimentos pedagógicos e administrativos aos mesmos. Formalmente foi criado um termo de cooperação entre as três empresas, de forma que os alunos que fossem, pela idade e pela aprovação, migrando da educação infantil para a educação fundamental, e desta para o ensino médio, onde obtivessem garantias de matrícula 
pelos próximos modulistas, e que possíveis ofertas de novas vagas só poderiam ser abertas depois de satisfeitas todas as demandas internas de alunos do consórcio.

Deste modo, perante os clientes (pais e demais responsáveis pelos alunos), devidamente acostumados com uma só escola, foi entregue este termo de cooperação, onde foi criado o cargo interorganizacional de supervisor geral dos módulos, sendo os próprios fundadores os supervisores, passando a mensagem ao público em geral de que não estariam se afastando totalmente das atividades na educação infantil e fundamental, mas sim propiciando aos sucessores a condição de estarem sob amparo interorganizacional até o momento que os fundadores entendessem que a apropriação dos conhecimentos fosse satisfatória, ao ponto de que fosse dada total autonomia aos sucessores.

\section{Os principais efeitos da criação do consórcio no ambiente individual e interorganizacional}

Dentre todo o material levantado em observações diretas e indiretas, análise documental, questionários, entrevistas e experimentos de campo, os principais efeitos descritos e observados da criação do consórcio em questão, pelos sucessores, funcionários de cada empresa e pelos fundadores, nas abordagens de gestão individual e interorganizacional, bem como nos aspectos pedagógicos, foram os seguintes:

\section{Gestão Interna}

Demandas operacionais: Funcionários (professores e técnicos administrativos) relataram que as decisões por parte da direção de cada escola ficaram mais rápidas e menos burocráticas desde que as escolas foram criadas. Que ficou mais fácil conseguir a atenção da direção da escola para demandas que antes demoravam mais para que retornassem ao proponente.

Gestão financeira e orçamentária: Os sucessores, ao passo que administram os módulos, acabam por ter responsabilidade direta nas questões financeiras. Foi criado um orçamento de receitas e gastos por cada escola, de modo que os sucessores possam usar deste instrumento para distribuírem seus recursos de forma minuciosa e gerencialmente agrupadas, e prestarem contas de sua gestão aos fundadores. 
Autonomia de decisões: Os sucessores reconhecem que antes de serem criados os módulos, as decisões estratégicas da escola-mãe eram tomadas quase que exclusivamente pelos fundadores, e que os sucessores pouco participavam ativamente dos processos de tomada de decisões. Que a partir da criação do consórcio, as responsabilidades foram redirecionadas aos sucessores e que se sentem mais autônomos enquanto efetivos sócios das empresas, muito embora em casos mais complexos, ainda consultem os fundadores.

Investimentos em estrutura física: Este ítem possui escopo principal, inicialmente, nas questões de que cada escola teve que investir de modo a possuir estrutura física individualizada (salas de aula, equipamentos e local administrativo). Cabe ressaltar que algumas áreas ainda são de uso comum, tais como os ginásios e as cantinas, por exemplo.

Planejamento: Sucessores e funcionários se posicionaram de forma equivalente sob este ítem. As principais impressões colhidas foram que, dado o porte de cada escola, os modulistas demonstraram mais foco na busca por propostas e soluções que antes eram de uma escola maior e mais complexa, dado que a escola-mãe contemplava todos os três níveis da educação básica. Que desde a modularização, cada escola planeja e executa suas atividades somente na sua área de atuação, sem precisar "concorrer” com os demais níveis de educação, sobre projetos e decisões para o ano letivo, por exemplo.

\section{Gestão Interorganizacional}

Transparência nas informações: Os fundadores, agora modulistas do ensino médio e supervisores dos demais módulos, reconhecem que no início do consórcio tiveram que impor métodos e cobranças periódicas sobre relatórios que cada módulo deveria de apresentar, tanto em questões administrativas como pedagógicas, de modo que os princípios fundamentais, norteadores da escola-mãe, fossem preservados. E que, com o passar do tempo, os sucessores tomaram uma postura mais proativa na prestação de contas, diminuindo assim as cobranças permanentes de entrega dos respectivos relatórios.

Velocidade de aprendizado: Os fundadores entendem que este item foi um dos mais efetivos entre os efeitos percebidos pela criação do consórcio. Que é visível a evolução profissional dos sucessores como proprietários das escolas, e que o amadurecimento no modo de conduzir as questões inerentes às suas responsabilidades vem crescendo de maneira satisfatória. 
Colaboração e competitividade: Este item é tradado pelos fundadores como aquele mais preocupante, mais arriscado, pois muito embora sejam empresas distintas, uma precisa da outra para se manterem abastecidas de alunos, por exemplo. Que a imagem de cada escola influencia na imagem do consórcio como um todo. Que necessitam de estabilidade e padrão no modo como são conduzidas as questões operacionais de cada módulo, de forma a evitar comparação interna entre as escolas, por professores e demais funcionários.

Autonomia e imagem dos sucessores: Salientam os fundadores que, dado o crescente aprendizado dos sucessores, quanto melhor suas posturas administrativas e maior número de decisões aprovadas, mais confiança os sucessores vão tendo. E que a imagem dos mesmos perante o público interno e externo vai evoluindo de maneira que a figura de "filhos dos donos" dê lugar aos reais donos do negócio.

Gastos operacionais: Posteriormente à criação do consórcio, cada escola teve que montar sua equipe de trabalho independente das demais. Deste modo, setores administrativos e pedagógicos foram individualizados, fato que resultou em mais profissionais contratados e, consequente, maior gasto operacional que anteriormente.

\section{Abordagem Pedagógica}

Qualidade de ensino: Como contraponto ao aumento dos gastos operacionais como indicador negativo, as estruturas pedagógicas de cada modulista resultaram em profissionais mais especializados e um número menor de turmas a dedicarem sua atenção. Assim, tanto professores como sucessores e fundadores estão de comum acordo que a atividade mais especializada promoveu reflexos positivos na qualidade de ensino. Alguns indicadores operacionais tais como: evasão escolar por falta de adaptação de alunos ingressantes, diminuição nos níveis de reprovação de alunos e médias mais altas das turmas no exame nacional do ensino médio (ENEM) e no programa de avaliação da vida escolar (PAVE), foram percebidos.

Seleção de pessoal: Cada modulista, na autonomia de que dispõe, criou processos de seleção para docentes, coordenadores e monitores de ensino mais tipificados em especialidades do que anteriormente, dado que a faixa etária dos alunos de cada módulo é logicamente menor que uma escola que atenda os três níveis da educação básica. Deste modo, por exemplo, professores que antes transitavam entre o ensino fundamental e o ensino médio, 
agora focaram suas atividades somente no módulo que atuam, tendo uma ação mais especializada do que generalizada, colaborando para melhoria do ítem qualidade de ensino.

Agilidade em processos: As propostas de projetos de ensino, atividades extra-classe e demais vivências acadêmicas encaminhadas pelos professores e coordenadores à direção de cada módulo, encontram, sob o ponto de vista dos requerentes, maior velocidade de feedback da direção dos módulos, do que anteriormente. Ressaltam que, quando uma escola só, as pautas entravam em fila para a aprovação e demoravam mais para serem discutidas, fator este que, por vezes, acabava atrasando ou até mesmo comprometendo o andamento de algumas práticas pedagógicas.

Investimentos em ferramentas educacionais: Para os professores, embora existam muitas ferramentas que facilitam a gestão da sala de aula, a preparação de conteúdo, provas e apresentações, anteriormente à criação do consórcio, a preferência em investimentos dessa natureza era dada pela capacidade da ferramenta ou do equipamento em transitar por todos níveis da escola. Relatam os mesmos que em alguns casos, se tornava difícil compatibilizar plataformas e conteúdos quando comparados ensino médio e ensino infantil, por exemplo. Deste modo, em um momento ou outro, pelo menos um dos três níveis de ensino acabara por ficar prejudicado dada a escolha do investimento. Com a concepção das escolas modulistas, os investimentos ficam a cargo de cada empresa, fato este que corrobora para investimentos mais especializados que anteriormente.

\section{CONSIDERAÇÕES FINAIS}

Entende-se que as abordagens adotadas pelo consórcio modular das escolas objetos deste estudo são complementares e incluem diversos fatores comuns, tal como o repasse da carteira de clientes, sistemas integrados de informações, especialização de conhecimento, bem como a necessidade de desenvolvimento de uma gestão interorganizacional mais eficiente, além do que os benefícios são compartilhados entre todos os atores envolvidos, em função da ausência de assimetria de poder entre as três escolas, que antes formavam uma só empresa, pertencentes ao consórcio modular em questão.

A opção pelo desmembramento de uma escola em uma estrutura modular de três escolas (uma de educação infantil, outra de ensino fundamental e outra de ensino médio) constituiu uma forma inovadora de organizar a formação de base dos alunos de um modo 
flexível, tendo implicações positivas ao nível de aprofundamento e especialização do desenvolvimento curricular, da organização administrativa das escolas e das práticas pedagógicas.

O consórcio modular parte do conceito de módulos como unidades de aprendizagem mais autônomas, que permitem aos professores, coordenadores e diretores de cada escola promoverem aos alunos a absorção de um conjunto de capacidades mais focadas em cada um dos públicos-alvo, através de atividades de aprendizagem mais cuidadosamente concebidas e focadas especializadamente em cada um dos segmentos de cada escola. Estes modulistas (cada escola) constituem os componentes especializados, completos em si mesmas e simultaneamente interligados, fazendo parte de um todo (consórcio modular) cuja estrutura interorganizacional permite que cada escola tenha autonomia e profunda especialização nas suas decisões.

Vários efeitos percebidos da criação do consórcio no ambiente individual e interorganizacional das empresas foram destacados ao longo do presente trabalho, de forma que possam ser incentivadas implantações desta prática em outras escolas. No tocante especialmente à sucessão familiar, o consórcio modular obteve êxito para a finalidade que foi proposto, de modo que fundadores e sucessores demonstram satisfação co os resultados alcançados até o presente momento.

Finalmente, o grande desafio do presente estudo foi a substituição do objeto empírico tradicional de consórcio modular em questão, de fábricas automotivas para uma escola. $\mathrm{O}$ esforço em adaptar e aplicar os conceitos relacionados especialmente à indústria automobilística para a sucessão familiar no ramo educacional, apresenta-se como a maior contribuição deste trabalho. Como contribuição à futuras pesquisas, sugere-se que sejam testados mais objetos empíricos onde o consórcio modular possa se encaixar como uma contribuição, no intuito de aprofundarem-se mais os conhecimentos e possíveis limitações desta prática inovadora.

\section{REFERÊNCIAS}

ANTUNES JÚNIOR, J. A. V. et al. O. Estruturação da plataforma de negócios com vistas à inovação: o sistema corporativo de inovação. XXIX ENCONTRO NACIONAL DE ENGENHARIA DE PRODUÇÃO. Anais. Salvador, 2009. 
BAARDI, V. A. Critical review of interventionist research. Qualitative Research in Accounting and Management, vol.7, num.1, p.13-45, 2010.

BENNETT, D; KLUG, F. Logistics supplier integration in the automotive industry. International Journal of Operations \& Production Management, v. 32 , n. 11, 2012.

BERNARDES, H. K. B. et al. Modularização: Simplificando a gestão e maximizando os resultados. Espacios. Vol. 34 (2), 2013.

BLOCH-POULSEN, J.; KRISTIANSEN, M. Power and contexts: Some societal conditions for organisational action research-Clashes between economic-management and pedagogicsocial discourses. International Journal of Action Research, v. 10.3, 2014.

BRAGA, A. X. V. Avaliação da aplicação da gestão interorganizacional de custos no ambiente de consórcio modular: competitividade por meio da estratégia de colaboração e redução dos custos globais das operações. Tese de Doutorado. Programa de Pós Graduação em Administração. UNISINOS, 2015.

CALDEIRA, A. Indicadores de competitividade empresarial para a formulação de estratégias. Revista Ibero-Americana de Estratégia, v. 3, n. 1, p. 87-100, 2004.

CASTELLS, M. The information age. Blackwell Publishers: Oxford, 1996.

CHEN, M. Competitor analysis and interfirm rivalry: toward a theoretical integration.

Academy of Management. Academy of Management Review, v. 21, n. 1, p. 100-134, Jan. 1996.

DORAN, D. et al. Supply chain modularisation: Cases from the French automobile industry. International journal of production economics, 106(1), 2-11, 2007.

DOZ, Y. L.; HAMEL, G. Alliance advantage: The art of creating value through partnering. Harvard Business Press, 1998.

DYER, J. H; SINGH, H. The relational view: cooperative strategy and sources of interorganizational competitive advantage. Academy of Management Review, v. 23, n. 4, p. 660-679, 1998.

DYER, J; NOBEOKA, K. Creating and managing a high-performance knowledge-sharing network: The Toyota case. Strategic Management Journal, v. 21, n. 3, p. 345-367, March, 2000.

EISENHARDT, K. M. Building Theories from case study research. The Academy of Management Review. New York, v. 14, n. 4, p. 532-550, out. 1989.

FIXSON, S.K. The multiple faces of modularity - a literature analysis of a product concept for assembled hardware products. Michigan: University of Michigan, Industrial and Operations Engineering, p. 2003-05, 2003.

FLORIANI, O; RODRIGUES, L. C. Sucessão empresarial: processo sucessório em empresas familiares. ENCONTRO DE EMPREENDEDORISMO E GESTÃO DE PEQUENAS EMPRESAS. Anais. Passo Fundo/RS, 2000.

GERSICK, K. E; ROSAS, R. M. De geração para geração: ciclos de vida das empresas familiares. 4. ed. São Paulo: Negocio Editora, 1997. 
HUNGER, V. B. Os desafios na sucessão familiar: a transcrição do conhecimento empresarial às novas gerações. IX ENCONTRO DE ESTUDOS SOBRE EMPRENDEDORISMO E GESTÃO DE PEQUENAS EMPRESAS. Anais. UPF. Passo Fundo/RS, 2016.

LODI, J. B. A Empresa Familiar. 5. ed. São Paulo: Pioneira, 1998.

LONGENECKER, J. Administração de pequenas empresas. São Paulo: Makron, 1997.

MARTINS, J. F; VIEIRA, A. V; MOURA, A. C. A profissionalização de uma empresa familiar e sua influência na cultura e na construção das identidades dos gestores. Destarte, 4(1), 2014.

MIKKOLA, J. H. Management of product architecture modularity for mass customization: modeling and theoretical considerations. IEEE - Transactions on Engineering Management, v. 54, n. 1, p. 57-69, 2006.

MILLER, T. D.; ELGARD, P. Defining modules, modularity and modularization. 13TH IPS RESEARCH SEMINAR. Proceedings. Fuglose, Denmark, 1998.

PELLEGRIN, I. Inovação: uma estratégia para o desenvolvimento industrial do RS. Porto Alegre: Fiergs/Citec (Conselho de Inovação e Tecnologia), 2008.

SAKO, M.; MURRAY, F. Modules in design, production and use: implications for the global automotive industry. INTERNATIONAL MOTOR VEHICLE PROGRAM (IMVP). Annual Sponsors Meeting, Proceedings. Cambridge Massachusetts, 2000.

TIDD, J. Innovation management in context: environment, organization and performance. International Journal of Management Review, v.3, n.3, 169-183, 2001.

TILLMANN, C; GRZYBOVSKI, D. Sucessão de dirigentes na empresa familiar: estratégias observadas na família empresária. Organizações \& Sociedade, v. 12, n. 32, p. 45-61, 2005.

OYADOMARI, J. C. T. Pesquisa intervencionista: um ensaio sobre as oportunidades e riscos para pesquisa brasileira em contabilidade gerencial. Advances in Scientific and Applied Accounting, v. 7, n. 2, p. 244-265, 2014.

OLIVEIRA, G. T.; MARTINS, R. A. Efeitos da Adoção do Modelo do Prêmio Nacional da Qualidade na Medição de Desempenho: estudos de caso em empresas ganhadoras do prêmio. Gestão \& Produção, v. 15, p. 167-179, 2008.

ROESCH, S. M. A. Nota técnica: Pesquisa-ação no estudo das organizações. In S. R. Clegg, C. Hardy, \& W.R. Nord (Orgs.), Handbook de estudos organizacionais: Reflexões e novas direções (vol. 2., cap. 6, p.118-123). São Paulo: Atlas, 2001.

SACHS, J. The activist teaching profession. The activist teaching profession Buckingham: Open University Press, 2003.

SERVIÇO BRASILEIRO DE APOIO ÀS MICRO E PEQUENAS EMPRESAS. No Brasil, 90\% das empresas são familiares. Disponível em SEBRAEDUC. http://www.sebraesc.com.br/newart/default.asp?materia=10410. Acesso em: 5 out. 2016.

SENGE, P. The fifth discipline: The fifth discipline the art and practice of the learning organization. Nova York: Doubleday-Currency, 1990. 
SUOMALA, P.; LYLY-VRJÄNÄINEN, J.. Interventionist Management Accounting Research: Lessons Learned. Research executive summaries, v. 6, n. 1, 2010, CIMA. Disponível em: www.cimaglobal.com.Acesso em: nov/2020.

VENTURA, L. C. A empresa e a sucessão. Patrimônio e sucessão: como garantir os herdeiros e os negócios. Antônio Carlos Cortese, et al (Organização de Luiz Kignel). São Paulo: Maltese, 1993.

ZAWISLAK, P. A. Uma abordagem evolucionária para análise de casos de atividade de inovação no Brasil. Ensaios FEE. Porto Alegre, v. 17, n. 1, p. 323-354, 1996. 